\title{
O RECONHECIMENTO DO OUTRO E A PRESTAÇÃO DE DIREITOS PELO ESTADO
}

\author{
João Victor Magalhães Mousquier ${ }^{1}$
}

\section{Resumo:}

O presente artigo consiste em uma análise da Teoria da Reserva do Possível como garantidora de direitos fundamentais à coletividade. Teoria essa aventada pelo Estado após a fixação da "era dos direitos". Essa era é resultado da afirmação dos direitos civis, políticos e principalmente, sociais para os cidadãos. Conforme esses cidadãos vão conquistando Direitos, migra o Estado para o Estado Democrático de Direito - com a consagração dos direitos civis e políticos. Inicia-se por esses direitos e destes haverá a fixação do Estado Social. Estado esse que assumiria o papel de vetor do progresso material e da justiça social, o que redundaria na consagração dos direitos econômicos, sociais e culturais. Tal progresso encontra-se à base e na gênese, portanto, de ambas as formas ou configurações do Estado moderno, a saber, o Estado Social. Contudo, a Reserva do Possível é uma tradução do limite orçamentário do Estado para o provimento de todos os direitos estabelecidos e permitidos. Uma das formas de se evitar um direito, é não reconhecê-lo em um Outro. Logo, quando o Estado deixa de reconhecer o Outro como detentor de direito, necessariamente a Reserva do Possível deixa de ser útil. Diante desse prisma, propõe-se usar a Reserva do Possível como, também, forma de reconhecimento do Outro pelo Estado, objetivando com isso que cidadãos sejam, na medida das suas desigualdades, reconhecidos e atendidos nos seus direitos fundamentais. Esse reconhecimento pode vir através dos ensinamentos de Hegel ao descrever uma forma de reconhecer o Outro juridicamente.

Palavras-chave: era dos direitos; Reserva do Possível; direitos fundamentais; Estado Social; Reconhecimento do Outro.

\section{INTRODUÇÃO}

O nascimento do Estado moderno é resultado de uma mudança paradigmática que alterou o contexto vivido em todos os setores: social-econômico-político-jurídico-individual. A pactuação entre Estado e cidadãos não mais súditos - faz com que esses mesmos passem a gozar de direitos individuais, até então estudados e tidos como naturais, agora devendo ser garantidos pelo próprio Estado.

Para tal, necessário um entendimento do que veio a ser a construção do cidadão/indivíduo, a sua autonomia psciquica-jurídica-social e a sua relação com outros seres humanos, quando decidido por viver em sociedade. Esta necessidade se explica ao pensarmos que o ser humano mantém constante contato - devido a sociedade - com outros e uns desses serão governantes e que, mesmo havendo determinações legais de atuação,

\footnotetext{
${ }^{1}$ Mestrando em Direitos Humanos pela Universidade Regional do Noroeste do Estado do Rio Grande do Sul - UNIJUí. E-mail: joao.mousquer@unijui.edu.br 
há certa discricionareidade que permite a aplicação de políticas públicas, por exemplo, fazendo com que o reconhecimento desses humanos seja considerado.

O Estado garantidor não foi um fim em si próprio e o Estado Prestador passou a imperar nas relações sócio-estatais, trazendo a figura dos custos dos direitos para a gestão estatal e seu eventual (sub)desenvolvimento. Com isso, a doutrina alemã inaugurou o questionamento sobre a prestação contínua do Estado e a possibilidade econômica, justificando ser necessário haver um mínimo existencial e uma reserva do possível. Contudo, tal entendimento não pode ser usado por esse mesmo Estado para justificar determinado fracasso na distribuição de direitos. Essa reserva, deve ser pré organizada e não a justificação em um momento posterior. A crueldade de sentenciar a falta de recursos para prestação de direitos não pode ser rotina, menos ainda regra. Uma melhor gestão pública determinará um melhor gasto, consequentemente uma maior prestação de direitos a serem gozados pelos cidadãos.

\section{O ESTADO-NAÇÃO E O RECONHECIMENTO DO OUTRO}

A “era dos direitos” inaugurou o Estado-nação. Essa “era” adveio, principalmente da Declaração Francesa e que teve como alicerce a inversão da soberania monárquica do absolutismo pela participação popular, ou seja, a figura do Leviatã passa a figurar em prol do homem e pela descoberta do indivíduo. Essa última descoberta caracterizou e fundamentou a diferenciação entre homem e cidadão. A rigor, como ensina o professor Luis Fernando Sgarbossa, em paráfrase a Ingo Wolfgang Sarlet, que se baseou no magistério de Antonio Enrique Perez Luño, esses direitos não surgiram no século XVIII na sua totalidade, mas sim, houve uma progressiva recepção de direitos, liberdades e deveres individuais que podem ser considerados os antecedentes dos direitos fundamentais.(SARLET, 2008)

Não se conseguirá, perfeitamente, compreender Estado-nação, na modernidade e pósmodernidade, sem a apreensão preliminar do conceito de nacionalismo. E, em acréscimo, ter o entendimento das revoluções e evoluções políticas no decorrer da história. Podemos afirmar que o nacionalismo manifestou-se na Europa no século XIX e início do século XX, constituindo um artifício ideológico para construir um modelo de Estado sobre conceito de nação, compreendida como fundamento de poder. Pode-se, ainda, compreender que o nacionalismo é um sentimento de pertença de um grupo em relação a uma tradição derivada de uma identidade histórica, geográfica, linguística ou cultural e, ao mesmo tempo, de diferença em relação a outros grupos. Percebese que esse foi utilizado como expediente para o projeto político de Estado em que a unidade política seja coincidente com a unidade nacional, no qual o Estado se caracterizasse como a expressão jurídica da nação. (SGARBOSSA, 2010). Foi à ideologia nacionalista que permitiu "fundar" um Estado-nação, na qual se constitui 
por uma noção de território, uma afirmação de cidadania, uma atividade jurídica, enfim, uma caracterização de determinada cultura.

Naturalmente, essa delimitação do homem natural em homem nacional promoveu a exclusão. Um homem só é nacional se pertencer a uma Nação, logo ele não pertencerá a outra e o outro não pertencerá a sua. Uma repulsa, uma objeção se posta diante do Estado na figura do homem cidadão nacional, sendo aquele fomentador ou não. Porém, os direitos naturais gozados e fruídos pelo homem cidadão livre, foram transformados em sociais e posteriormente em fundamentais, o que, socialmente e juridicamente, promoveu uma exclusão, um não reconhecimento.

Nessa realidade, a lei e compromisso social são baseados nesta divisão radical, que separa indivíduos e a entidade coletiva em sujeitos e sujeitados. Daqui, reúne-se o núcleo da cidadania.

Essa exclusão, natural para o Estado e esquizofrênica e paradoxal para o homem, produziu e ainda produz, as lacunas sociais. Com o contrato social estabelecido, leis e sujeitos tornam-se intimamente ligados, sendo aquela usada como definidora social de contingente, ou seja, a naturalidade do reconhecimento e zelo do humano pelo homem somente terá(?) aplicabilidade se houver previsão legal. Os homens são detentores de direitos. Isto é o ápice da humanidade. Contudo, o reconhecimento jurídico, ou o reconhecimento que a normatividade deveria promover, é, por vezes, antagônica a aquilo que as Declarações promoveram para o próprio homem.

Ocorre que o choque entre situações se estabeleceu de tal forma nessa auto fundação e nessa representatividade que o alicerce das Declarações está sob custódia. Essas Cartas promoveram a liberdade e esta é a principal aspiração e conquista da modernidade conquanto subjetivamente o sujeito moderno torna-se livre para decidir o que é bom para si próprio e suas ações não podem ficar restritas à aplicação inquestionável de normas e regras. A consciência e a vontade modernas tornam-se legislativas: sujeitos agora podem examinar as regras por si próprios e podem rejeitá-las e substituí-las. (DOUZINAS, 2009)

Isso, pelas palavras de Costas Douzinas em análise de Kant reflete a autonomia kantiana, quando o homem moderno torna-se sujeito da lei, em duplo sentido: ele é o legislador, o sujeito que provê a lei e o sujeito jurídico, sujeitado à mesma na condição de que participou de sua legislação. $\mathrm{O}$ reconhecimento da implicação da vontade na ação é um movimento tipicamente moderno e distingue a razão prática da razão pura. Além disso, a proclamação do Eu não apenas como quem provê a lei, mas também como sujeito, assinala a inauguração da concepção moderna de autonomia e autodeterminação.(DOUZINAS, 2009)

A existência da identidade própria, do Eu, consequentemente, leva ao surgimento do Outro e que, física, politica e juridicamente gera dependência mútua. Consciente ou não. A consciência de si, contudo, constitui a unidade de si mesmo no ser (outro) de alguém e é alcançada ao ver a si mesmo no Outro e ao aceitar o Eu como a 
identidade da identidade e da não identidade.(ZIZEK, 1996) O sujeito na sua perfeita consciência, necessita e por isso mantém a sua separação deste como essencial à sua existência. Nesse sentido a consciência de si não apenas nega a divisão entre o Eu e o Outro, mas também a preserva. Contudo esse reconhecimento funciona se for mútuo. Ou seja, o Eu deve ser reconhecido por alguém que este também reconheça como humano-cidadãonacional. Esse reconhecimento está entrelaçado à aceitação de características de um tipo que na verdade são compatíveis com a sua. (DOUZINAS, 2009) Esse reconhecimento muito mais identitário do que humano faz com que haja lacunas sociais e déficit de direitos.

Essa necessidade do outro foi observada por Freud e Lacan na psicanálise.(QUINET, 2012) O ser humano sente falta e por isso deseja o outro. Não deseja em posse, mas deseja para se ver, se reconhecer ou querer não se reconhecer. Por isso o contratualismo justifica tal conceito, pois o homem é reflexo do contexto, subordinado e ao mesmo tempo livre.

Isso ocorre na pós-modernidade porque o conceito do Outro foi traduzido no conhecimento que o Eu tem deste. Houve a simplificação do Outro - mesmo que seja coletivo - para o meu conhecimento. Ele é reflexo do que o Eu sabe dele e não necessariamente do que o Outro realmente o é. Essa é a tese de Kant. O Eu constitui o mundo com base no meu esquema e nas minhas categorias. Segundo eles, sem isso o Outro está inacessível. Essa visão modificou o "avanço" social, natural, pois o "ser que está diante de mim no círculo da reflexão é o meu ser, que foi tomado equivocadamente por ser como tal." O EU reflete o OUTRO pela bagagem histórica e relativista.

Por isso para Kant o Direito do Outro é na verdade um direito meu. O sujeito promulga uma lei para obedecer, mas para isso idealiza uma comunidade universal de seres similares, quando não idênticos ao ego tanto em razão ou em inclinações. Essa universalização uniformiza a ética. Essa lei universal na verdade é uma lei moral universal, advinda do ego, onde o EU reflete no OUTRO o ego.

Essa visão leva a um separatismo humano. Naquele que eu não consigo refletir o outro, pois eu não o conheço, logo é diferente de mim, eu o afasto. Só tenho perto de mim o que similar a mim é. Aqui se identifica um conflito entre moral, universal e direito, pois a essência desse separatismo é o livre arbítrio, no qual, influenciado inconscientemente pelo meio, o sujeito se moldará.

O certo é que para se ter um direito é necessário reconhece-lo. Só se reconhece em outro, logo antes de Eu ter um direito, o que, necessariamente o Outro tenha. Como se o direito do Outro precedesse o meu. Esse outro é uma pessoa única, singular. Não é o sujeito abstrato da lei nem o homem do liberalismo. O Outro tem lugar, tempo, gênero, história, necessidades e desejos. Isso em entendimento posto, é o que sobrevive nos direitos humanos hoje. A necessidade do dever moral de salvar e proteger o outro.

A ética da alteridade afirmará que o Outro vem primeiro. Ele é condição de existência da linguagem, do Eu e da Lei. Para a alteridade o Outro não pode ser reduzido ao Eu. Para alteridade o Outro é um "rosto". O rosto 
não representa uma presença ausente e não pode, portanto, tornar-se um dado cognitivo. $\mathrm{O}$ rosto também não é um semblante. O rosto é símbolo de uma categoria. Logo, para a alteridade: os direitos humanos representam concretizações do direto da outra pessoa e do meu dever, e minha liberdade, antes de se tornar antagônica para outros, é a liberdade da responsabilidade e da fraternidade. (DOUZINAS, 2009)

Mister a observação de que nessa diapasão histórica-política-jurídica o homem, detentor dos direitos proclamados nas Declarações passou a se conceituar - até porque com as mesmas ele se auto fundou-, também, em cidadão. Com isso, umbilicalmente uniu-se a humanidade e a política. Logo o reconhecimento do Eu pelo Outro perdeu base essencial no momento em que o homem se tornou cidadão-político-nacional. Fundamentando assim o entendimento de que essa bipartição do humano passou a permitir a exclusão, separação dos humanos pelo homem e pelo Estado.

Na realidade o homem exclui outro humano por não reconhece-lo como tal. Há o início de uma crise de identidade dentro do psíquico do ser na qual o Eu não reconhece o Outro. Esse não reconhecimento, obviamente, sofre influencia das determinações jurídicas e políticas, haja vista que biologicamente um humano reconhece outro, mas juridicamente, o mesmo ser pode - mas não deveria - desconhecer este próximo na sua totalidade, em um perfeito paradoxo. Ao agregar ao direito natural, na abstração natural os elementos da cor, etnia, sexo (...), se decompôs a originalidade e se construiu muros ou abismos entre os humanos. Talvez, porque pouco a humanidade preocupou-se em conceituar homem, humano. Se descreveu características desses. Se acrescentou condições a esses, sejam elas políticas ou jurídicas, mas sua essência ficou perdida no tempo e no espaço. Sob outro ponto de vista, pode-se denominar esse não reconhecimento em exclusão social.

\section{O SURGIMENTO DOS DIREITOS DE SEGUNDA GERAÇÃO E SUA EFICÁCIA}

Em apertada síntese, pode-se afirmar que a persistência dos problemas de exclusão social pré-existentes, aliados aos problemas sociais engendrados pelo advento do modo de produção capitalista e pelos avanços da técnica oriundos da Revolução Industrial, assim como as crises originadas de eventos históricos de primeira grandeza, tais quais as duas grandes guerras mundiais e a crise de 1929 foram eventos importantes para que o Estado promulgasse, pela sua representatividade social a segunda geração dos direitos universais. ${ }^{2}$

Século marcado por convulsões bélicas, crises econômicas, mudanças sociais e culturais e progresso técnico sem precedentes (mas não sem contradições), o século XX é, muito mais do que o século anterior, a era das ideologias e das revoluções. Desembocam nele todas as grandes correntes filosóficas e acelera-se o ritmo dos

\footnotetext{
${ }^{2}$ Para uma narrativa do processo de transformação do Estado em referência, remate-se a NUNES, A.J A. Neoliberalismo e direitos humanos. Rio de Janeiro: Renovar, 2003, pp 01-08.
} 
eventos políticos. É, portanto, o século em que o Direito Público sobre poderosíssimos embates e em que a fase liberaldo Estado constitucional vai seguir-se uma faze social. (MIRANDA, J. Op. cit. p.91)

Esses direitos derivados das bases capitais e da economia ou, senão derivados, originados, são, no entendimento de Luis Fernando Sgarbossa os direitos de segunda geração ou dimensão, reconhecidos como direitos econômicos e sociais. Direitos que não são obtidos, inicialmente, por embate contra o Estado, mas sim, direitos garantidos por intermédio do Estado.

Tais direitos, reconhecidos sob a égide do Estado-nação, seja no plano interno, seja no plano internacional, inauguram uma compreensão renovada do papel da pessoa humana: se, por um lado, quanto aos direitos alcunhados de primeira geração, o Estado desincumbia-se de seus deveres fundamentais precipuamente através de abstenções, por outro, quanto aos direitos ditos de segunda geração, o Estado cumpre suas obrigações precipuamente através de um agir positivo, de atuação no sentido da concretização dos direitos, seja regulando o mercado - como no caso das intervenções de domínio econômico representadas pela legislação trabalhista, por exemplo-, seja outorgando ele mesmo o direito às prestações sociais - como no caso da previdência social contemporânea, organizada e gerida sob a égide da estatalidade. Tal segunda onda de direitos modifica substancialmente a compreensão dos deveres estatais, alterando a concepção mesma de Estado, que, de Estado de Direito ou Estado Democrático de Direito passa àquela de Estado Social.(SGARBOSSA, 2010)

Naturalmente as transformações sociais, principalmente as promovidas pelas alterações econômicas serão refletidas no âmbito jurídico. O Direito Público sofrerá, assim como o Constitucional de forma direta qualquer alteração que os elementos acima descritos produzirem, também em reflexo à sociedade.

Portanto, não menos natural, a convivência cidadã tratou de demonstrar que nem todos os iguais perante a Lei gozavam dessa premissa, assim como outras. Até porque, a igualdade legal é muito mais um marco normativo político do que uma realidade, no contexto atual - e assim não poderia ser diferente-. É nessa distância entre realidade e normatividade que orbita os Direitos Humanos. Mas essa obrigação estatal em prover igualdades e demais premissas, nas palavras de José Joaquim Gomes Canotilho traduz-se na radicação da ideia da necessidade de garantir o homem no plano econômico, social, cultural, de forma a alcançar um fundamento existencial-material, humanamente digno, onde o mesmo passou a fazer parte do patrimônio da humanidade, independente da adesão aos postulados marxistas.(CANOTILHO, 2003)

Marx, por sua vez, afirmava que o homem era um ser social, logo, em entendimento, pode-se vislumbrar, que também para ele, somente com o reconhecimento de um para com outro é que se formaria uma sociedade, nas suas premissas de benesses.(DOUZINAS, 2009) Somando-se a esse conceito, traz a luz o preceito estabelecido por Boaventura de Souza Santos que prima por uma necessidade de gestão econômica pública além de reclamar pela complexidade sempre crescente da economia de matriz capitalista. Resulta dizer que uma 
segunda transformação foi o reconhecimento político das externalidades sociais do desenvolvimento capitalista a politização de algumas dimensões da questão social. (SANTOS, 2005) Contudo, se para que haja igualdade entre os homens, por exemplo, é necessária a observação das matrizes de capitais, e com isso tem-se, novamente, a limitação do homem dentro de uma nação, o que, como já sabemos, leva a exclusão de outro homem. Homem enquanto espécie e não gênero.

$\mathrm{Na}$ atualidade os direitos fundamentais são considerados, por um lado, como direitos subjetivos do individuo e, por outro lado, como elementos fundamentais da ordem objetiva da coletividade. Desse modo, no primeiro plano, os direitos fundamentais constituem direitos subjetivos fundamentadores de status, os direitos fundamentais dos direitos básicos jurídico-constitucionais do particular, como homem e como cidadão.(HESSE, 1998)

Porém, ao momento em que tais direitos passam a ingressar o rol daqueles que constitucionalmente são previstos e dispostos (ou deveriam ser), há uma abrangência maior do meio possibilitatório em que o Estado é agente. Isto resulta numa adaptação do Estado para com a situação, visto que tais novos direitos possuem estruturas diferentes dos seus derivantes.

Esse advento de novos direitos fundamentais acaba por evidenciar os aspectos prestacionais e a necessária postura predominantemente ativa do Estado para a efetivação dos direitos. Significa, nos ensinamentos de Konrad Hesse que as tarefas do Estado não mais se esgotam na proteção, conservação, só ocasionalmente, intervenção. O Estado da Lei Fundamental é Estado que planifica, guia, presta, distribui, possibilita primeiro a vida individual como social e isso é posto para ele, pela fórmula do estado de direito social, por causa da Constituição, como tarefa.(HESSE, 1998)

José Canotilho, na sua constante lucidez diz que tal índole, como por exemplo direito ao trabalho, a uma remuneração adequada ou o direito à habitação são, todavia, de estrutura totalmente diferentes como aquela os direitos fundamentais clássicos. Eles não se deixam realizar já por ele serem organizados, respeitados e protegidos, senão pedem ações estatais para a realização do programa social contido neles, que requerem regularmente um tornar-se ativo não só do legislador, mas também da Administração.

Em resumo, são esses direitos que asseguram aos cidadãos, em sentido estrito, a obtenção de algo através do Estado - saúde, educação, segurança social, etc-. É exatamente tal diferença crucial entre os direitos fundamentais em geral e os direitos fundamentais sociais e sua relação de tensão para com o princípio democrático e para com a liberdade de conformação do legislador e do administrador que levarão à crise de inefetividade das disposições jusfundamentais sociais, a qual se encontra, em última análise, na reserva do possível. Além de garantidor o Estado também passa a ser prestacional. 


\section{A PRESTAÇÃO DE DIREITOS COMO FATOR DE DESENVOLVIMENTO ESTATAL}

Nesse seara, importante destacar que, em áreas diversas e esta não seria diferente, países periféricos principalmente ex-colonias europeias - são acometidos pelo mal crônico do desenvolvimento retardado, fruto dos mais diversos fatores. Nesses países, é consenso o saber de que o Estado Social jamais foi plenamente implementado.

Prova disso é a pontuação do Brasil perante o coeficiente de $\mathrm{Gini}^{3}$, sendo-a de 0,59. Índice esse capaz de ficar atrás de países como Colombia, México, Uruguai no quesito igualdade. Ou ainda na classificação do Brasil no Indice de Desenvolvimento Humano, promovido e divulgado pela $\mathrm{ONU}$, na qual este país se mantém entre $83^{\circ} \mathrm{e}$ $86^{\circ}$ entre as nações. Ou seja, o Brasil é um dos países mais desiguais do mundo. Contudo, a preocupação maior deve se ater ao fato de que o país é desigual de forma estável, ou seja, durante toda a sua história houve e se manteve a desigualdade.

Conforme nos ensina Fábio Nusdeo, em observação de Luis F. Sgarbasso, em termos de desenvolvimento é irrelevante o tamanho absoluto da economia de um país, estando o subdesenvolvimento caracterizado, dentro outros fatores, por indicadores tais quais baixa renda per capita, grande desigualdade na distribuição de renda, taxas de natalidade e mortalidade elevadas, preponderância do setor primário da economia na composição da renda, baixos padrões médios de consumo e qualidade de vida (instrução saneamento, adequação alimentar) dentro outros fatores.(SGARBOSSA, 2010)

Independentemente da razão, seja ela por atraso industrial, déficit financeiro, carência de condições filosófico-político e sociais, nosso Estado (gênero) não conseguiu implementar na completude o Estado Social. Talvez por ser um Estado fruto de uma cópia ideológica, sem que houvesse tido uma revolução social para tal. Revolução não no sentido bélico, mas no sentido de ajustamento, enquadramento e formação social. Cópia de um sistema externo, perfeitamente justo, mas fruto de uma demanda social histórica contemporânea local que foi universalizada apenas no seu resultado e não na sua materialização.

Tal contexto, no momento atual, ainda sofre com o agravamento da situação em virtude do atingimento da hegemonia neoliberal nos países latino-americanos subdesenvolvidos, bem como pelo enfraquecimento dos Estados nacionais em virtude da globalização econômica e da dependência internacional.

\footnotetext{
3 O Coeficiente de Gini é uma medida de desigualdade desenvolvida pelo estatístico italiano Corrado Gini, e publicada no documento "Variabilità e mutabilità"( "Variabilidade e mutabilidade"em italiano), em 1912. É comumente utilizada para calcular a desigualdade de distribuição de renda, mas pode ser usada para qualquer distribuição. Ele consiste em um número entre 0 e 1 , onde 0 corresponde à completa igualdade de renda (onde todos têm a mesma renda) e 1 corresponde à completa desigualdade (onde uma pessoa tem toda a renda, e as demais nada têm). O índice de Gini é o coeficiente expresso em pontos percentuais (é igual ao coeficiente multiplicado por 100). Enquanto o coeficiente de Gini é majoritariamente usado para mensurar a desigualdade de renda, pode ser também usado para mensurar a desigualdade de riqueza. Esse uso requer que ninguém tenha uma riqueza líquida negativa.
} 
Mais uma vez, fazendo valer dos ensinamentos de Boaventura de Souza Santos é de se constatar que a relativa perda do protagonismo do Estado, sendo embora um fenômeno generalizado, tem implicações muito diferentes conforme se trate de Estados do centro da semiperiferia ou da periferia do sistema mundial. Num contexto de crescente desigualdade entre Norte e Sul, os Estados periféricos e semiperiféricos - ao cumprimento das determinações do capital financeiro e industrial transnacional, determinações, por sua vez, estabelecidas pelas organizações internacionais controladas pelos Estados centrais. Essas determinações, frequentemente apresentadas em combinações estranhas de liberalismo econômico e de proteção dos direitos humanos, abalam a tal ponto a já de si frágil componente social do Estado, que esses países assumem a ideia da crise do EstadoProvíncia sem nunca terem usufruído verdadeiramente deste. ${ }^{4}$

Novamente se percebe que não basta uma Carta Magna para que direitos sejam concedidos, garantidos, ou ainda, prestados. É necessária uma estruturação Estatal por completa, não apenas a utopia de que a universalização de direitos promoverão o melhor viver social. Esta situação, também agravada pelos reveses da ideologia e dos programas neoliberais e a fragilização advinda da globalização econômica neoliberal, o que representa o arrefecimento de uma atuação já tímida no sentido da implementação dos direitos sociais e o desmantelamento das conquistas já consolidadas, pode ser denominada de pré contratualismo que é a consistência de um processo de exclusão preliminar, consistência em bloqueio do acesso à cidadania em relação a grupos sociais que a ela ensaiavam e que tinham expectativa de a ela aceder.(Sgarbossa, 2010) Pode, também, serem descritos como situação de direitos sociais natimortos, pois nunca estiveram inteiramente implementado.

\section{A RESERVA DO POSSÍVEL COMO FATOR DECISIVO SÓCIO-ESTATAL}

Em continuidade, naturalmente, a sociedade demanda por esses direitos de forma gradativa, conforme suas certezas de que são sujeitos que possuem esse direito. Diante de tal, as Ações, que se baseiam na Carta Cidadã e na ventilação de que o Estado deve garantir acesso aos mesmos crescem e demonstram os números dessa necessidade. Inúmeras teorias de garantismo foram fixadas e postas aos operadores do direito. Uma delas é a teoria, já exaustivamente debatida na nossa Suprema Corte, da reserva do possível.

Contudo esta é bem mais antiga do que sua suposta origem jurisprudencial alemã. Pode-se afirmar, baseado em dados históricos, que este instituto já estava sendo observado, mas sob outra leitura, desde o século VI, sendo registrada nos anais do II Concílio de Tours, na qual, observava-se que a orientação dada as pequenas comunidades era de que deveriam cuidar de seus pobres no limite da sua necessidade.(SGARBOSSA, 2010) Mas há uma certa boa vontade nesse visão ao se fazer uma analogia à Reserva do Possível. Porém é possível afirmar que

\footnotetext{
${ }^{4}$ SANTOS, B. de S. Op. cit. p.155. Segundo o autor, "Em consequência destas alterações, o princípio, nunca acabado, da comunidade, retrocedeu para um estado de marginalização ainda maior."
} 
desde que a economia, administração e direito passaram a integrar a gestão do Estado, a disponibilidade de recursos já faz parte do pensamento que condiciona o direito à proteção social.

A reserva do possível possui como origem a discussão acerca da efetivação de direitos sociais prestacionais. Em síntese apertada, é a discussão, possível por ambas as partes, acerca do custeio de direitos fundamentais e a previsão financeira para custear esses mesmos. Sabido é que o Estado, seja sob qual forma e condição for, planeja seus gastos, assim como planeja sua arrecadação. Possui uma economia e uma administração voltada para o melhor gasto e a melhor arrecadação. Sendo esse Estado obrigado a prestar determinados direitos aos seus cidadãos, cabe àquele que promova uma gestão capaz de suprir essa demanda, sem prejudicar demais ramos do Estado. É um ramo do direito que discute, em seu mérito, o acesso a direitos sociais, como a educação e a saúde e políticas públicas de cunho social.

O óbice disto é que estamos versando sobre uma administração imprecisa. Imprecisa não pela qualidade, mas pela vinculação de prever o futuro para planejar os gastos baseada em uma arrecadação advinda do presente. Trata-se de uma gestão para com números incertos no futuro e arrecadação determinada no presente.

Porém, mesmo que possa parecer um truísmo, é relevante ressaltar que a reserva do possível é matéria que versará sobre direitos sociais pleiteados junto a Fazenda Pública, ou seja o Estado.

Quanto ao mérito, de se observar, ainda, as oportunidades em que a reserva do possível foi fundamento para denegação de direitos sociais e as oportunidades em que foi afastada pelo Supremo Tribunal Federal e pelo Superior Tribunal de Justiça. Mencionando as Cortes, importante relatar o mais célebre caso em que a Suprema Corte enfrentou o tema da reserva do possível. Tratou-se da Arguição de Descumprimento de Preceito Fundamental de número 45, relatada pelo Ministro Celso de Mello e julgada no ano de 2004. Tal ação foi iniciada pelo Partido da Social Democracia Brasileira - PSDB- tendo como objeto o veto presidencial a dispositivo da Lei de Diretrizes Orçamentárias - LDO- cujo teor era no sentido de que seriam consideradas como ações e serviços de saúde "a totalidade das dotações do Ministério da Saúde, deduzindo os encargos previdenciários da união, os serviços da dívida e a parcela das despesas do ministério financiada com recursos do Fundo de Combate e Erradicação da Pobreza. ${ }^{5}$

A ação discutia que o veto presidencial acarretaria na redução dos recursos a serem efetivamente aplicados em ações e serviços públicos de saúde, em contrassenso ao disposto pelo artigo 198 , $\mathbb{S} 2^{\circ}$ da Constituição Federal. Tal contenda versou sobre a possibilidade/legitimação da intervenção judicial no que se refere a implementação de políticas públicas efetivadoras de direitos econômicos, sociais, culturais, em face da liberdade de conformação do legislador. Traduz pela questão dos custos dos direitos e da escassez de recursos.

No resultado dessa Ação a Suprema Corte perfilhou o entendimento no sentido da inoponibilidade do arbítrio estatal em face a direitos constitucionalmente consagrados, afirmando a relatividade da liberdade de conformação do legislador e esposando entendimento no sentido da necessária preservação do mínimo existencial dos indivíduos.

\footnotetext{
${ }^{5}$ Integra do voto do Ministro relator, Celso de Mello.
} 
(...) a realização dos direitos econômicos, sociais e culturais - além de caracterizar-se pela gradualidade de seu processo de concretização financeiro subordinando às possibilidades orçamentárias do Estado, de tal modo que, comprovada, objetivamente, a incapacidade econômico-financeiro da pessoa estatal, desta não se poderá razoavelmente exigir, considerada a limitação material referida, a imediata efetivação do comando fundado no texto da Carta Política. Não se mostrará lícito, contudo, ao Poder Público, em tal hipótese, criar obstáculo artificial que revele - a partir de indevida manipulação de sua atividade financeira e/ou político-administrativa - o ilegítimo, arbitrário e censurável propósito de fraudar, de frustrar, e de inviabilizar o estabelecimento e a prestação, em favor da pessoa e dos cidadãos, de condições materiais mínimas de existência. (...) a cláusula da reserva do possível - ressalvada a ocorrência de justo motivo objetivando aferível - não pode ser invocada, pelo Estado, com a finalidade de exonerar-se, dolosamente, do cumprimento de suas obrigações constitucionais, notadamente quando, dessa conduta governamental negativa, puder resultar nulificação ou, até mesmo, aniquilação de direitos constitucionais impregnados de um sentido essencial de fundamentalidade. (...) Vê-se, pois, que os condicionamentos impostos, pela clausula da reserva do possível, ao processo de concretização dos direitos de segunda geração - de implantação sempre onerosa -, traduzem-se em um binômio que compreende, de um lado, (1) a razoabilidade da pretensão individual/social deduzida em face do Poder Público e, de outro, (2) a existência de disponibilidade financeira do Estado para tornar efetivas as prestações positivas dele reclamadas. Desnecessário acentuar-se, considerando o encargo governamental de tornar efetiva a aplicação dos direitos econômicos, sociais e culturais, que os elementos componentes do mencionado binômio (razoabilidade da pretensão + disponibilidade financeira do Estado) devem configurar-se de modo afirmativo e em situação de cumulativa ocorrência, pois, ausente de qualquer desses elementos, descaracterizar-se-á a possibilidade estatal de realização prática de tais direitos. ${ }^{6}$

Percebe-se do quanto o julgado da Corte Suprema recepcionou a reserva do possível, admitindo seu cabimento ao menos em tese, ressalvando apenas ser inadmissível sua alegação infundada ou a utilização das receitas públicas para furtar-se o administrador do cumprimento de suas obrigações constitucionais.

Em resultado corrente das nossas Supremas Cortes, pode-se perceber que a Teoria da Reserva do Possível não é aplicável em matéria de preservação dos direitos à vida e à saúde, justamente por entender que ambos são bens máximos e impossíveis de ter sua proteção postergada. A Reserva do Possível é, simploriamente, um sinônimo da reserva de orçamento.

A Reserva do Possível, também, é expressamente concebida como o limite imposto pela razoabilidade, como aquilo que o individuo pode racionalmente esperar da sociedade, fórmula esta presente literalmente naqueles precedentes e repetida na doutrina germânica pelos mais variados autores, como Robert Alexy e Konrad Hesse. (SGARBOSSA, 2010)

Contudo, pode-se observar, em possível aparência a transposição do conceito de reserva do possível implicou sua mutação, de modo que esse sentido originário restou marginalizado na doutrina, recaindo a ênfase significativamente na escassez de recursos e na questão de custos dos direitos, características esta que vem dando a tônica do debate nacional acerca do construto.

\footnotetext{
${ }^{6} \mathrm{ADPF} 45 / \mathrm{DF}$, publicada no Diário da Justiça da União, Seção 1, no 84, terça-feira, 4 de maio de 2004, p. 13.
} 
De uma exigência essencial por razoabilidade e proporcional nas prestações postuladas do Estado Social, sempre no âmbito da dicotomia indivíduo-sociedade, levadas em consideração as circunstâncias históricas, jurídicas, políticas, filosóficas e socioeconômicas concretas, passou-se a compreender a reserva do possível ora como limitação fática aos direitos fundamentais, ou seja, como a limitação imposta ao exercício dos direitos sociais com base na escassez real ou econômica; ora como limitação jurídica, vale dizer, como a limitação imposta ao exercício dos direitos sociais com base na escassez ficta, ou legal, ora como a limitação imposta ao exercício dos direitos sociais com base na ausência de razoabilidade ou proporcionalidade de pretensão, e, ainda, por vezes como todos estes aspectos, conjuntamente, ou alguns deles, combinadamente. (SARLET, 2008)

Neste segmento, importante trazer a baila a discussão sobre o custo dos direitos. Pois, se o Direito é a ciência do dever-ser, parece intuitivo que o domínio de suas regras seja o poder-ser. A leitura econômica do Direito, desenvolvida nos Estados Unidos da América, traz a tona a observação da quantificação, ou seja, se os recursos são escassos, se deve indagar, para além das questões relativa a quem atender e dos prognósticos de cura, acerca de uma possível maximização dos resultados, exemplificando com uma quantificação - numero de vidas salvos por cada mil reais gastos. (AMARAL, 2001).

Sob essa premissa, continua Gustavo Amaral:

Após explorar argumentos tais quais a polissemia e a indeterminação semântica da expressão direito, necessário se faz citar Norberto Bobbio, quando este descreve que os direitos são sine die, que por sua vez decorrem das normas programáticas da Constituição, uma vez que tais normas não ordenam, proíbem ou permitem hic et nunc, mas ordenam, proíbem e permitem num futuro indefinido, e sem prazo de carência claramente delimitado. (AMARAL, 2001)

Naturalmente há uma finitude ontológica dos recursos materiais. Talvez na mesma proporção haja uma infinitude de necessidades. Nesse diapasão superficial, pode-se entender que dedicar larga parcela, por exemplo, de fundos públicos à moradia popular equivale a dar um tratamento diferencial aos pobres, levando a um entendimento de que há favorecimento a estes em detrimento de outros. Com a certeza de que há fim nos recursos, abre-se oportunidade para não vincular a obrigação em prestar algo simplesmente por estar na lei. Assim o sendo, pela finitude já dita, nem todos serão atendidos. A questão essencial do tema, parecer ser a vinculação a escassez pela naturalidade dos recursos ou pela má gestão.

No contexto da má gestão, para Flávio Galdino (2005) há uma injusta alocação de recursos escassos na sociedade brasileira e um enorme agir do Poder Judiciário nos gastos públicos. Em uma metáfora, deveria haver uma balança (sempre a balança quando se trata de direitos) onde a racionalidade econômica deva contrabalancear a racionalidade jurídica. Isso, dentro do modelo atual do Brasil não existe, justamente pela falta de racionalidade social, naquilo que o já citado Boaventura de Souza Santos revolução cultural social. Socialmente há o entendimento de que alguns direitos são gratuitos. 
Como o Estado passou a adotar modelos econômicos cada vez mais universais e menos regionais, o ordenamento jurídico, logo seu conceito e sua aplicabilidade, não detiveram mesma sorte (?). Deste modo, raras são às vezes, senão inexistentes, as decisões judiciais que consideram os efeitos econômicos.

Sob este aspecto, tomar os direitos a sério significa tomar a sério a escassez dos referidos recursos públicos, de modo que os custos dos direitos devem influir na sua conceituação, notadamente no que se refere a direitos subjetivos públicos. Em primeiro lugar, tais direitos não podem ser considerados absolutos. Afirma-se peremptoriamente: nada que custa dinheiro é absoluto. (GALDINO, 2005) Não é possível formular uma definição de direito abstraindo da realidade concreta, ou seja, das condições de cada tempo e lugar - daí falarmos nós em conceito pragmático. Assim, o tempo e o espaço, juntamente com os condicionantes econômicos e financeiros deveriam definir o que é direito. Todavia, os custos dos direitos não devem ser considerados simples óbices à concretização dos direitos, mas devem ser compreendidos, como constitutivos de direitos.

Para Galdino, em virtude da inclusão da expressão eficiência no artigo 37, caput, da Constituição da República de 1988, levada a cabo pela Emenda Constitucional no 19/98, resta promovida a eficiência a fator da legitimação da Administração Pública, e não somente, como imposição constitucional a todo o sistema jurídico e a todos os operadores do direito.(GALDINO, 2005)

Mas, aproveitando a vinculação à eficiência, logo a boa ou má-gestão, entende-se que se deve voltar ao tema da escassez para se debater de forma mais concreta.

A escassez, em um conceito econômico, pode ser definida como a situação que se caracteriza quando a máxima produção potencial de um bem não se encontra em grau suficiente para satisfazer todas as necessidades na medida em que os recursos disponíveis são ilimitados. A escassez, portanto, na economia, é qualificadora dos bens econômicos e pré-condição dos preços.

Pode a escassez ser dividida, caracterizada. E numa dessas, se apresenta como real, econômica, ficta e jurídica. Pela primeira, entende ser decorrente da efetiva inexistência concreta do recurso. Já a segunda é compreendida com ao escassez decorrente da indisponibilidade jurídica, isto é, em virtude de norma jurídica que determine pontual alocação dos recursos em detrimento de outras. A despeito de todo o apelo ao realismo feito pela doutrina dos custos dos direitos, de se notar que a mesma se baseia, em regra, em uma escassez do tipo ficcional, qual seja, aquela engendrada pela peça orçamentária. A escassez aqui denominada ficta ou jurídica enquadra-se no tipo intitulado por John Elster escassez artificial e apresenta-se na possibilidade de poder o Estado, por uma decisão política, suprir a demanda.(SGARBOSSA, 2010)

Portanto essa escassez consiste, essencialmente, na indisponibilidade jurídica, paralela a inexistência econômica. Pode ser uma escassez temporária, ou seja, momentânea e por tal artificial. Perfeitamente a é superável. Trata de alocação de recursos economicamente existentes em determinados setores implicando o não 
atendimento de outras necessidades, por uma decisão disjuntiva do órgão ou agente com competência em matéria alocativa, seja ele qual for. Geralmente é essa escassez arguida pelo Estado para não adimplir com os direitos fundamentais.

Em outras palavras, a compreensão da escassez ficta como base à reserva do possível traz problemas no que concerne à pretensa autoevidência e racionalidade irrefutável da reserva do possível, aproximando-o de teorias mais antigas a amplamente discutidas e seriamente contestadas e muitas, na atualidade, a caminho do esquecimento ou já em pleno desuso, haja vista sua insustentabilidade. Leva em consideração, como óbice à exigibilidade dos direitos a alocação decidida pelos órgãos competentes - escassez ficta - notadamente pelo legislador e pelo administrador público, remete, necessariamente, em primeiro lugar, à teoria de separação dos poderes, à teoria da soberania do legislador eà doutrina das questões políticas.(SGARBOSSA, 2010)

A soberania do legislador, também conhecida como soberania orçamentária do legislador se insere na conceituação da reserva do possível, na qual vinculam a existência a uma dependência da intervenção legislativa e administrativa. Assim, os direitos econômicos e sociais existem, portanto sob a reserva do possível ou da soberania orçamentária do legislador, ou seja, da reserva da lei instituidora das políticas públicas, da reserva da lei orçamentária e do empenho por parte da Administração.

Nesse sentido, o temor fica vinculado a um erro material do legislador quando este não prever na formulação da lei todos as necessidades existentes, assim como possibilidade orçamentária. Dentro desse temor, a literatura jurídica mais atualizada tem considerado perfeitamente possível a correção da alocação de recursos orçamentários pelo Poder Judiciário sempre que estes ostentem caráter arbitrário ou não traduzam as prioridades constitucionalmente consagradas. Considerar, ainda, a escassez ficta ou jurídica como sendo apta a sustentar a inexigibilidade dos direitos fundamentais sociais implica uma aproximação ou mesmo uma identificação da reserva do possível da teoria das normas programáticas ${ }^{7}$ e da doutrina das normas constitucionais de eficácia limitada.(SGARBOSSA, 2010)

Naturalmente sabe-se que o direito provido pelo Estado, na sua efetivação e desde que essa onere o mesmo - todos os direitos irão onerar - possuem sua dependência de existência vinculadas aos recursos públicos que, por sua vez, dependem da arrecadação tributária.

De todo o aduzido por escassez econômica e escassez jurídica, acredita-se que a reserva do possível, quando alegada com base em limitações jurídicas, como lei orçamentária, configura-se como restrição a direitos fundamentais. Essa alegação de ausência de disponibilidade jurídica-financeiro sobre recursos existentes, seja por

\footnotetext{
${ }^{7}$ No fundo normas programáticas, sob um determinado aspecto, nem são normas jurídicas verdadeiras e próprias, porque o programa que elas traçam está destinado a ser atuado pelo legislador quando as circunstâncias oferecem esta possibilidade; as sim que, definitivamente, embora o valor ético e político do empenho seja inegável, a atuação concreta é deixada ao futuro legislador, que poderia também não cuidá-la absolutamente, ou fazê-lo em mínima parte, e que, em todo caso, não violaria a Constituição se não o fizesse. (AZZARATI, G. apud BILHALVA, J.M.)
} 
força de lei orçamentária, seja em virtude de dispositivo legal que imponha padrões de austeridade fiscal, caracteriza uma situação em que a decisão alocativa consubstanciada no diploma legal implica restrição a direitos fundamentais sociais, sendo interpretada, portanto, a partir de tal ponto de vista, como restritiva de tais direitos fundamentais.

Arguir tal limitação cerceando os direitos fundamentais é matéria combatida pelo princípio da proibição do excesso, que nas palavras do constitucionalista português José Joaquim Gomes Canotilho significa que, antes considerado um subprincípio densificador do Estado de direito democrático, agora este, no âmbito específico das leis restritivas de direitos, liberdades e garantias, que qualquer limitação, feita por lei ou com base na lei, deve ser adequada (apropriada), necessária (exigível) e proporcional (com justa medida). (CANOTILHO, 2003) Podese entender a partir desse ensinamento, que toda e qualquer limitação legal que promova restrição de algum direito, deverá ser proporcional à necessidade.

Sob esses ditames também se assenta o princípio da proporcionalidade, quando se observa seu tríplice aspecto: adequação, necessidade e proporcionalidade em sentido estrito. Esse, sob a inteligência de Robert Alexy se traduz como:

O princípio ou máxima da proporcionalidade guarda estreita relação com a questão das possibilidades fáticas e jurídicas de cumprimento de normas constitucionais consubstanciadas em princípios. O princípio da adequação e da necessidade encontram-se vinculados com as possibilidades fáticas, ao passo que a máxima da proporcionalidade em sentido estrito vincula-se às possibilidades jurídicas.(ALEXY, 2005)

Porém, não se deve deixar de observar que os ensinamentos do professor Canotilho, demonstram que no ordenamento jurídico há uma clausula de proibição de retrocesso. Esta, para aquele, está que uma vez concretizada as normas constitucionais instituidoras fundamentais, seja através de outorgas de prestações, de políticas públicas ou da criação de instituições, por desenvolvimento legislativo, não seria possível sua supressão sem compensação. O princípio da proibição social pode formular-se assim: o núcleo essencial dos direitos sociais já realizado e efetivado através de medidas legislativas ("lei do serviço de saúde") deve considerar-se constitucionalmente garantido, sendo inconstitucionais quaisquer medidas estaduais que, sem criação de outros esquemas alternativos ou compensatórios, se traduzam, na prática, numa "anulação", "revogação" ou "aniquilação" pura e simples desse núcleo essencial.(CANOTILHO, 2003)

Com isso, também está demonstrado a garantia a segurança, que em normativamente taxada é denominada segurança jurídica. Mas se vai além, pois também se pode vislumbrar neste princípio uma garantia mais ampla, que alcança situações não protegidas pelas vedações ortodoxas da irretroatividade de leis mais gravosas ou de disposições que garantem o direito adquirido, o ato jurídico perfeito e a coisa julgada. 
Ingo Wolfgang Sarlet (2008), retratando lições de Luís Roberto Barroso, José Joaquim Gomes Canotilho e Vital Moreira, consiga que o desenvolvimento legislativo no sentido de um mandamento constitucional acarreta a incorporação do avanço de sua supressão, de modo que o direito prestacional, uma vez desenvolvido legislativamente, resta acobertado por uma dimensão negativa, com caráter de direito de defesa, oponível contra o estado quando este pretenda contra ele atentar.

Portanto, a alegação pelo Estado para a não prestação de direitos fundamentais sob guarita da reserva do possível desmancha-se pelos dedos. Mesmo que a escassez seja algo latente, e cada vez mais observável e sentida, os direitos fundamentais postos em Cartas Magnas devem ser, em política econômica, antevisto pelos administradores para que sejam fornecidos dentro da proporção orçamentária. Não é porque não foi orçado que não se deve prestar tais direitos.

Neste paradigma importante é a observação do mínimo existencial ${ }^{8}$. A priorié de se saber se os direitos econômicos, sociais e culturais exigem a garantia de um núcleo essencial como condição de mínimo de existência. Das várias normas sociais, econômicas e culturais possível deduzir-se um princípio jurídico estruturante, na qual os está consagrado na Carta Magna, em seu tão citado artigo 5º quando afirma os direitos sociais taxativamente. Logo, todos têm um direto fundamental a um núcleo básico de direitos sociais e estando o Estado faltando com a prestação, dever-se-á considerar o mesmo como atentador das obrigações jurídicos-sociais constitucional e internacionalmente impostas.

Destaca-se, com isso, que um patamar mínimo de direitos fundamentais sociais e econômicos constitui condição de possibilidade da fruição de outros direitos, inclusive de direitos clássicos de liberdade ou defesa. (SGARBOSSA, 2010)

Porém, o mínimo existencial é algo incolor, pois pouco, se há, delimitação do que se considera ou o que compõem esse mínimo. É significativo que se comece hoje a considerar o que constituiria um núcleo fundamental de direitos econômicos, sociais e culturais. Há os que, com a Comissão Interamericana de Direitos Humanos, argumentam que tal núcleo seria constituído pelos direitos ao trabalho, à saúde e a educação. Em recentes reuniões internacionais de peritos também se tem referido, como possíveis componentes daquele núcleo, os chamados "direitos de subsistência" (direito à alimentação, direito à moradia, direito aos cuidados médicos, direito a educação).

\footnotetext{
${ }^{8}$ SARLET, I. W, Op. cit. p.19: Embora a construção do Mínimo existencial, em sua compreensão atual, remonte à teoria jusplubicista e a decisões alemãs do Século XX, conforme se verá, existe um protótipo da ideia, aproximado ao conceito contemporâneo de mínimo vital, no Speenhamland Parliament Act britânico, de 1975, que consagrou o direito de todo trabalhador a um mínimo vital, para si e para sua família, conforme ensina Robert Holcman: "Uma decisão do Parlamento reconheceu o direito de todo trabalhador a uma "renda de subsistência" dependente do preço do trigo e do número de seus filhos, obrigando assim as comunas a outorgar um complemento de renta a todos aqueles que não ganhavam tal mínimo". HOLCMAN, R. Op. cit.p. 16
} 
Por outro lado, em força contrária ao entendimento acima exposto, Ingo Sarlet (2008) sustenta a impossibilidade de uma pré-definição fechada e apriorística de seu conteúdo, defendendo sua variabilidade no tempo e no espaço e mesmo com relação a diferentes direitos fundamentais sociais. Nessa contextualização é importante a compreensão da distinção entre o mínimo vital ou fisiológico - aquilo que é imprescindível à vida em termos biológicos - e mínimo existencial, consistente na assecuração de um mínimo de inserção do indivíduo, em tendencial igualdade, na vida social.

Assim, a própria fundamentação no princípio da dignidade da pessoa humana, dignidade essa que possui uma inequívoca dimensão sociocultural, exige que, além de não se definir aprioristicamente o conteúdo do Mínimo Existencial, não se reduza este último ao mínimo vital, eis que a mera existência digna.

\section{Com isso, sacramenta Scarlet:}

Se a indeterminação do conteúdo do Mínimo Existencial constitui, por um lado, um problema teórico, por outro é exatamente tal indeterminação, diretamente relacionada à dimensão sociocultural da ideia de vida digna, que permite sua adaptação adequada às variações das necessidades no tempo, no espaço e em função das características peculiares pessoais ou de cada núcleo familiar. De outro, se o conteúdo do mínimo existencial e os níveis de satisfação das necessidades que integram tal mínimo permanecem problemáticos, existem necessidades que fundamentam direitos que inegavelmente inserem-se dentro do conceito de mínimo existencial e, simultaneamente, fazem parte do mínimo vital ou fisiológico, como direito a alimentação. (SARLET, 2008).

Com isso, o meio termo parece a melhor solução, permitindo que a indeterminação seja sempre relativa, sendo superável em virtude da natureza dos direitos em questão ou ainda de circunstâncias históricas e sociais concretas, permanecendo, portanto, hígido o construto de mínimo existencial para a finalidade de salvaguardar o núcleo essencial dos direitos fundamentais sociais.

Importante salientar que a ideia de que tanto o mínimo existencial quanto o conexo principio da dignidade humana constituem, a despeito de seu conteúdo relativamente indeterminado - mas determinável por ocasião da analise dos casos concretos - barreiras às restrições aos direitos fundamentais, de modo que medidas comissivas ou omissivas - estas ultimas marcadamente importantes no âmbito de direitos sociais prestacionais da estabilidade que violem o mínimo existencial ou a dignidade da pessoa humana restam inquinas de inconstitucionalidade.(SGARBOSSA, 2010)

Por fim, pode-se afirmar que o mínimo existencial desempenha um papel análogo ao legitimamente desempenhado pela reserva do possível, no âmbito do estado social constitucionalizado, mas em sentido oposto. A se ver: por um lado a reserva do possível representa em suma conformação original um limite máximo ou teto para o Estado social, excluindo pretensões exageradas e irrazoáveis, conforme já visto, por outro lado, o mínimo existencial desempenha o papel de um patamar mínimo ou piso para o Estado Social, excluindo a omissão estatal que comprometa a existência digna da pessoa. 
Sob a ótica do direito hegeliano, a primordial função dos direitos é permitir que o reconhecimento seja estabelecido, possibilitando a constituição de uma personalidade em sua completude. A subjetividade passa pelo reconhecimento mútuo o Outro, e os direitos são um instrumento intermediário necessário e indispensável nesse processo. Naturalmente os direitos são intersubjetivos, já que não podem ser atributos de uma existência atomizada.(DOUZINAS, 2009)

O reconhecimento do Outro pelo Eu, também permeia o Estado quando este reconhece juridicamente o cidadão. Não se está travando um embate entre o contrato social ou os ideias liberalistas. Mas, tenta-se, demonstrar que o próprio Estado cega-se para determinada parcela da sociedade, excluindo esse da vida digna. Não havendo o reconhecimento natural pela sociedade entre os indivíduos, politicamente o Estado pode agir para "reconhecer" essa parcela através da reserva do possível, destinando parte das receitas para a promoção de direitos fundamentais.

Essa relação jurídica resultante desse reconhecimento Estatal, pressupõem uma moralidade universalista que compoe o pano de fundo da lei e assegura que as pessoas sejam tratadas como fins e não maios. Em segundo lugar, o reconhecimento do outro como pessoa jurídica é o efeito do fato de que ele desfruta de autonomia e responsabilidade morais e possui direitos legai. Esta tipo de reconhecimento é tipicamente chamado de respeito (à dignidade). Finalmente, o reconhecimento jurídico conduz ao respeito próprio. O respeito próprio é o resultado da percepção de que eu também sou capaz de uma ação moral e que, como outros, sou um fim em mim mesmo. (DOUZINAS, 2009)

Todavia, dentro das observações de Hegel, para que haja esse reconhecimento, é necessário haver a configuração da cidadania. Essa por sua vez, nada mais é do que o exercício dos direitos políticos e a ativa associação nas atividades da comunidade. $\mathrm{O}$ ato de reconhecer o ser como cidadão traz a politica a centralidade $\mathrm{e}$ insere a comunidade no núcleo da subjetividade. Significa dizer, que ao ser reconhecido pela Reserva do Possível, esta estará promovendo uma política pública social em face do capital. Douzinas expõe as concepções de hegelianas-marxistas de que os direitos humanos - aqui os reconhecidos e promovidos pela Reserva do Possível podem ser apresentados como naturais e eternos, mas são altamente históricos e contingentes. Podem ser declarados acima da política, mas são a construção de relações políticas e da luta contínua por reconhecimento (do grupo ou individual). (DOUZINAS, 2009)

Entretanto, a ideologia de Hegel - pressupõe um sistema jurídico universalista sob o qual as pessoas estendem seu respeito um ao outro por serem sujeitos jurídicos cientes das leis e de outras normas que criam e protegem os direitos. Além disso, relações jurídicas promovem o respeito próprio: o reconhecimento de que o Eu é moralmente autônomo e tem a capacidade de adquirir os mesmos direitos e deveres de todos os outros. Tais pressupostos e efeitos do reconhecimento jurídico ou da posse de direitos existem apenas em uma comunidade 
que tem legislado para todos - só funciona sob essas precondições e efeitos. (DOUZINAS, 2009) Novamente, o reconhecimento por parte do Estado através de políticas públicas que asseguram a efetivação de direitos pela Reserva do Possível trata de uma garantia jurídico-estatal para o ser, enquanto sujeito político e jurídico.

Esse reconhecimento estatal pode ser considerado, também, a observação de uma característica dos Direitos Humanos, qual seja: a extensão dos direitos a novos grupos e a sua ampliação.

Ao haver reconhecimento, naturalmente haverá a supressão da opressão. Opressão como uma negação do autodesenvolvimento adquire inúmeras formas, passando pela marginalização até a exploração econômica. Esse reconhecimento mutuo também é resultado dos cidadãos como agentes autodeterminantes decorrente da livre participação no processo democrático de tomada de decisões e da sua ampliação da política para outras áreas da vida social.

A continua ampliação do número de detentores de direitos políticos e a expansão da lógica da participação pública e política para áreas e atividades ate agora privadas auxilia-nos a compreender a relação entre cidadania e universalidade. Cada ampliação (ou redução) dos direitos políticos aumenta (ou diminui) a definição institucional de um determinado governo; ela literalmente move as fronteiras da sociedade para frente e para trás. A ideia de uma entidade política, de um espaço social incorporado, simbolizado por Deus, por um rei, por um soberano ou pela lei, é desmantelada toda vez que um grupo maior ou menos que antes é admitida a novos direitos e procedimentos participatórios. (Douzinas. p. 295)

Em conclusão, tanto pela exposição da Reserva do Possível e pelo reconhecimento do outro, também por Hegel, pode-se afirmar que os direitos humanos representam expressões de luta e por reconhecimento entre os cidadãos, luta essa que pressupõe e constrói a comunidade política. A ideia de reconhecimento mutuo não foi considerada na teoria dos direitos, mas está implícita na ação dos direitos e nas novas reinvindicações de direitos. Muitos aspectos do reconhecimento adquirem a forma dos direitos e todos os direitos são, nesse sentido, políticos, eles estendem a lógica do acesso público e da tomada de decisões e partes cada vez maiores da vida social.

Em que pese a prestação de direitos pelo Estado - direitos humanos atuais-, entende-se que, a opção da Assembleia Geral das Nações Unidas de produzir dois Pactos, sendo o primeiro regulatório da matéria de direitos civis e políticos e o segundo versando sobre direitos sociais, econômicos e políticos, além de ser uma pequena disputa de força entre os Estados Capitalistas e os Socialistas pós-guerra, deveu-se, também, ao entendimento de que os primeiros direitos eram auto aplicáveis, ou seja, versavam sobre direitos baratos, sendo passível de cobrança imediata, enquanto que os segundos eram programáticos e demandavam realização progressiva, ou seja, versavam sobre direitos de alto custo. Tanto é que, como resultado, o Pacto regratório dos primeiros direitos obteve fiscalização e controle mais efetivos para sua implementação do que os segundos direitos do segundo pacto. 


\title{
CONCLUSÃO
}

Não se consegue olvidar mais da função estatal enquanto este na figura moderna da sua existência. Também se observa que o Estado, seja em qual espaço geográfico se encontra, é um reflexo automático dos seus cidadãos.

O reconhecimento ou não de um ser humano não pode mais ser tratado como algo natural, mesmo que justificável por ciências, uma vez que os direitos humanos, postos como fundamentais ou não - pois isso depende da formação jurídica de cada Estado - são a metafísica da modernidade e compõem a ética universal para um reconhecimento e um desfrute melhor de direitos. Para tal, o desenvolvimento do Estado está intimamente ligada a garantia e prestação de direitos fundamentais por parte deste. A figura do mínimo existencial e da reserva do possível é totalmente válida enquanto táticas de administração que objetivam configurar o Estado como equânime perante seus cidadãos. Contudo, não se pode descontextualizar tal tática, usando-a, usualmente ao contrário, para deixar de prestar esses mesmos direitos, sob a alegação, justamente, de haver reserva do possível.

Ao mesmo tempo o Estado deve possuir mecanismos de defesa aplicáveis ao próprio Estado, uma vez que uma das formas de prestação e garantia dos direitos fundamentais se dá por meio de políticas públicas. Essas são aplicáveis e deveriam ser planejadas para determinada população, inclusive por tempo determinado, mas para haver sua perfectibilização, somente com o devido reconhecimento destes dentro da estrutura social o Estado poderá atuar de forma qualificada.

Com isso, tentou-se figurar o cidadão perante o Estado e esse perante aquele, para que o desenvolvimento de um refletisse, proporcionalmente, no desenvolvimento de outro.

\section{RECOGNITION OF RIGHTS AND THE PROVISION OF OTHER STATE}

\begin{abstract}
:
This article is an analysis of the Theory of Possible Reserve as guarantor of fundamental rights to the community. This theory mooted by the state after setting the "rights era." This was the result of the assertion of civil, political and primarily social for citizens. As these citizens are gaining Rights, migrates the state to a democratic state - with the consecration of civil and political rights-. Starts for these rights and these will be the setting of the welfare state. State that you assume the role of vector material progress and social justice, which would result in the consecration of the economic, social and cultural. Such progress is based on the genesis and therefore both forms or configurations of the modern state, namely the welfare state.

However, the Reserve is a possible translation of the limit state budget for the provision of all rights established and allowed. One way to avoid a right, it is not recognizing it in an Other. Therefore, when the State fails to recognize the Other as having rights, necessarily Reserve Possible stops being useful. Given this perspective, it is proposed to use the Reserve as possible, also in recognition of the Other State, aiming thus to be citizens, the extent of its
\end{abstract}


inequalities, recognized and treated in their fundamental rights. This recognition can come through the teachings of Hegel to describe a way of recognizing the Other legally.

Keywords: rights era; Reserve Possible; fundamental rights, the welfare state; Recognition of the Other.

\section{REFERÊNCIAS BIBLIOGRÁFICAS}

AMARAL, Gustavo. Direito, Escassez \& Escolha. Rio de Janeiro: Renovar, 2001.

ALEXY, Robert. Teoria da Argumentação jurídica. A teoria do discurso racional como teroia da justificação jurídica. Trad. Zilda H. S. Silva. 2a Edição. São Paulo: Landy, 2005.

BAUMAN, Zygmunt. Modernidade Líquida. Rio de Janeiro: Zahar, 2001

BOBBIO, Norberto. A era dos direitos. Rio de Janeiro: Elsevier, 2004

CANOTILHO, José Joaquim Gomes. Direito Constitucional e Teoria da Constituição. $7^{\text {a }}$ Ed.. Coimbra: Almedina, 2003.

DOUZINAS, Coastas. O FIM dos Direitos Humanos. São Leopoldo: Editora Unisinos, 2009.

GALDINO, Flavio. Introdução à Teoria dos Custos dos Direitos. Direitos não nascem em árvores. Rio de Janeiro. Lumen Juris, 2005.

HESSE, Konrad. Elementos de Direito Constitucional da República Federal da Alemanha (Grundzuge des Verfassungsrechets der Bundersrepublik Deutschland). Trad. Luíz Afonso Heck. Porto Alegre: Sergio Antonio Fabris Editor, 1998.

NASIO, J. D. Cinco Lições Sobre A Teoria De Jacques Lacan. Tradução, Vera Ribeiro - Rio de Janeiro: editora Zahar, 1993.

NETO, Diogo de Figueiredo Moreira. Direito, Poder e Estado. São Paulo. Ed. Fórum. 2011.

NUNES, Antônio José Avelãs Nunes. A crise atual do capitalismo: capital financeiro, neoliberalismo, globalização. São Paulo: Editora Revista dos Tribunais, 2012.

PADUA, Jose Augusto. Desenvolvimento, justiça e meio ambiente. Belo Horizonte. Ufmg. 2009

PAULA, Ana Paula Paes de. A administração pública brasileira entre o gerencialismo e a gestão social. Belo Horizonte. CEPEAD-UFMG. 2005.

Quinet, Antonio. Os outros em Lacan. Rio de Janeiro: editora Zajar, 2012.

SANTOS, Boaventura de Souza. Para um novo senso comum: a ciência, o direito e a política na transição paradigmática: A crítica da razão indolente contra o desperdício da experiência. v. 1. $5^{\text {a }}$ ed. São Paulo: Cortez, 2005. 
Org. Semear outras soluçôes. Os caminhos da biodiversidade e dos conhecimentos rivais. Rio de Janeiro: Civilização Brasileira, 2005.

SARLET, Ingo Wolfgang (org). Direitos fundamentais, orçado e "reserva do possível ". Porto Alegre: Livraria do Advogado, 2008.

JUNIOR SAULE, Nelson (Org). Direito Urbanístico - vias jurídicas das políticas urbanas. Porto Alegre: Sergio Antonio Fabris Editor. 2007.

SGARBOSSA, Luís Fernando. Crítica a teoria dos custos do direito. Porto Alegre: SERGIO ANTONIO FABRIS EDITOR, 2010

STIGLITZ, Joseph E. Globalização - a grande desilusão. Lisboa: Terramar. 2002.

ZIZEK, Slavoj (org). Um Mapa da Ideologia. Rio de Janeiro: Editora Contraponto, 1996.

Trabalho enviado em 24 de maio de 2014.

Aceito em 12 de agosto de 2014. 